2018-04

The relationship between exposure to

natural and urban environments and

children's self-regulation

Jenkin, $\mathrm{R}$

http://hdl.handle.net/10026.1/10691

10.1080/01426397.2017.1316365

Landscape Research

Taylor \& Francis (Routledge)

All content in PEARL is protected by copyright law. Author manuscripts are made available in accordance with publisher policies. Please cite only the published version using the details provided on the item record or document. In the absence of an open licence (e.g. Creative Commons), permissions for further reuse of content should be sought from the publisher or author. 


\section{Landscape Research}

\section{The relationship between exposure to natural and urban environments and children's self-regulation}

\section{Rebecca Jenkin, Ian Frampton, Mathew P. White \& Sabine Pahl}

To cite this article: Rebecca Jenkin, Ian Frampton, Mathew P. White \& Sabine Pahl (2017): The relationship between exposure to natural and urban environments and children's self-regulation, Landscape Research, DOI: 10.1080/01426397.2017.1316365

To link to this article: http://dx.doi.org/10.1080/01426397.2017.1316365

曲 Published online: 11 Jul 2017.

Submit your article to this journal $₫$

View related articles $\sqsubset$

View Crossmark data $₫$ 


\title{
The relationship between exposure to natural and urban environments and children's self-regulation
}

\author{
Rebecca Jenkin ${ }^{\mathrm{a}}$, Ian Frampton ${ }^{\mathrm{a}}$, Mathew P. White ${ }^{\mathrm{a}}$ and Sabine Pahl ${ }^{\mathrm{b}}$ \\ aEuropean Centre for Environment and Human Health, University of Exeter Medical School, Truro, UK; ${ }^{b}$ School of \\ Psychology, Plymouth University, Plymouth, UK
}

\begin{abstract}
Research suggests that children living in areas with more greenspace may have better self-regulation, but to date no studies have investigated this capacity immediately following exposure to natural vs. urban environments. To explore this, two studies using between-subjects experimental designs were conducted. Participants, between eight and eleven years old, completed a delay of gratification task (as an indicator of self-regulation) before and after a short ( $3 \mathrm{~min}$ ) video of either a natural or built environment or a control display. Potential cognitive and emotional mechanisms underpinning any self-regulation effects were explored using a selective attention task (Stroop test) and by monitoring mood (adapted Cantril's ladder). Results were mixed. Supporting earlier work, post-test delay of gratification scores were significantly better after exposure to a natural than urban environment, however, compared to controls, it appeared that this effect was due to the depleting effect of the built condition, rather than any restorativeness of the natural condition. Although we also found a marginally significant increase in mood after exposure to the natural environment, this did not mediate the effects of environment on self-regulation.
\end{abstract}

\section{KEYWORDS}

Self-regulation; natural environments; children; greenspace; mood

\section{Introduction}

Self-regulation is the ability people have to exert control over their thoughts, feelings impulses and behaviour (Vohs \& Baumeister, 2011). Theoretically, it has been associated with both cognitive and emotional elements (Baumeister, Heatherton, \& Tice, 1994). People normally use self-regulation to conform to personal standards (for example their ideals and morals), or standards of others such as social expectations (Baumeister, Vohs, \&Tice, 2007). Self-regulation failure has been linked to behaviours such as smoking, gambling and procrastination (Baumeister \& Heatherton, 1996).

Importantly for the present paper, it has also been suggested that reduced exposure to natural environments (for example through urbanisation) may be undermining the self-regulation capacities of both adults (Kaplan \& Berman, 2010) and children (Faber Taylor, Kuo, \& Sullivan, 2002). The aim of the current paper is to further explore this claim and investigate whether even a relatively short exposure to nature during the school day can help children's self-regulation capacities, operationalised in the current research using a delayed gratification paradigm. Evidence in support of such a suggestion could have important implications for educational practice and helping children maintain attentional capacity and emotional well-being during their school day. 


\section{Background}

A growing body of literature supports the hypothesis that exposure to natural environments may be beneficial for different facets of children's wellbeing (McCurdy, Winterbottom, Mehta, \& Roberts, 2010). For instance, there is evidence that moving home to a more natural setting (Wells, 2000), and going to a school with more surrounding greenspace (Dadvand et al., 2015), can result in significant improvements in cognitive abilities. Indeed, Faber Taylor and Kuo (2009) found evidence that even a brief walk through a park resulted in increased attentional ability (the ability to focus and direct attention) among a sample of children with attention deficit hyperactivity disorder, compared to walking through either a downtown or residential area. Children's emotional well-being may also be aided by exposure to natural settings (Ashbullby, Pahl, Webley, \& White, 2013; Kahn, 1997; Wells \& Evans, 2003).

Although these cognitive and emotional outcomes are important in themselves, the current research explores a further outcome, specifically a child's self-regulatory capacity. Self-regulation in childhood is important because it has been linked to issues such as childhood obesity (Graziano, Kelleher, Calkins, Keane, \& Brien, 2013; Nederkoorn, Coelho, Guerrieri, Houben, \& Jansen, 2012; van den Berg et al., 2011) and poor academic achievement (Matthews, Ponitz, \& Morrison, 2009; Moffitt et al., 2011). In one study children's self-regulation in relation to the amount of greenspace surrounding their homes was explored (Faber Taylor et al., 2002). Results indicated that girls who had greener views from their home (obtained by asking parents to report how'natural' the children's views were from their homes) had better self-regulation, as they had higher scores on tests of concentration, impulse inhibition and delay of gratification (compared to girls with less green views). On the other hand, the boys' results showed only a slight positive relationship between the two that was not significant.

To date, it appears that experimental studies exploring the immediate effect of exposure to natural environments on self-regulation have not been carried out with children. Experimental studies with adults have shown that exposure to natural environments can have a positive impact on an individual's ability to control impulses (Beute \& de Kort, 2014), and delay gratification (Berry, Sweeney, Morath, Odum, \& Jordan, 2014). These studies build on Attention Restoration Theory (ART; Kaplan, 1995), which states that natural environments are beneficial for attention because they are 'restorative', engaging involuntary attention and thus allowing our directed attention to recover. It has been hypothesised that self-regulation draws its energy from the same resource as directed attention, hence why natural environments are beneficial for both attention and self-regulation (Kaplan \& Berman, 2010).

On the other hand, there is evidence suggesting that affective state can influence self-regulation, in that individuals in bad moods have less self-regulation (Leith \& Baumeister, 1996; Seeman \& Schwarz, 1974) and positive mood can restore self-regulatory capacity (Tice, Baumeister, Shmueli, \& Muraven, 2007). If affect is the mechanism underlying the restorative effect of natural settings this would be evidence for Stress Recovery Theory (SRT; Ulrich, 1983; Ulrich et al., 1991). Specifically, SRT argues that modern urban environments offer a range of potentially threatening stimuli (fast cars, strangers, noise), which can lead to negative mood states and feelings of stress. By contrast 'non-threatening' natural environments pose less demand on individuals and exposure to these environments can help individuals 'recover' from the stress of modern life. Given SRT's focus on emotional processes it was necessary to also include measures of mood in the current work to understand the interplay of cognitive and emotional processes among children.

\section{Overview of the current research}

In sum, the aim of the current studies was to explore the relationship between exposure to urban and natural environments and children's self-regulation. Using two experiments, our first hypothesis was that children's self-regulatory capacities would significantly increase after a short exposure to a natural environment and significantly decrease after exposure to an urban environment. Crucially Lee, Williams, Sargent, Williams, and Johnson (2015) showed that a short $40 \mathrm{~s}$ viewing of a simulated green roof could aid cognition in adult participants in a simulated office setting. In a similar fashion, the 
current research looked at virtual exposure for children in a real school setting. If even short exposures during the school day are able to affect self-regulation there could be important benefits for children's learning. Our second hypothesis was that these effects would be driven by an underlying mechanism, specifically attention (as proposed in ART) or positive affect (as proposed by SRT). Therefore, attention and positive affect should also increase in natural environments, and decrease in urban environments.

\section{Study 1}

\section{Methods}

\section{Participants and design}

Following ethical approval ${ }^{1} 79$ children (40 females) aged eight to eleven years old participated in the study from three Primary Schools in Cornwall, UK. The schools were recruited through convenience sampling and were all in rural locations. A between-subjects design was used, with pre- and posttest measures. There were three conditions: a natural environment condition, an urban environment condition and a control condition. Videos were used as the intervention, with the control group viewing a video of neither environment. Participants were randomly allocated to condition using their participant number.

Before condition allocation, all participants took part in what was intended to be an 'ego-depletion' task ${ }^{2}$, i.e. keeping a straight face whilst watching a funny video (Baumeister et al., 1998). Following the standard ego-depletion paradigm, the aim was to ensure all participants would have 'depleted' their 'ego' by having to suppress a natural emotional response. In practice, however, nearly half of the children were unable to avoid laughing (the original paradigm was used with older undergraduate students) and there were no significant differences in subsequent results as a function of whether the children suppressed their emotions or not during the video. Consequently, the effects of this initial task are not considered further below.

\section{Measures}

\section{Self-regulation}

Self-regulation was measured using a delay of gratification task. Based on items developed by Seeman and Schwarz (1974) each participant was given five pairs of choices, and for each pair the option was between a small, immediate (having it'now') reward and a larger, delayed (having it'in a week') reward (see Table 1). There were two different versions of the task for pre- and post-testing. In the original version, participants circled their choices, but the ethics committee was concerned this may be difficult for those with reading difficulties in this study, and so to make it inclusive for all children, the options

Table 1. Delay of gratification choices.

\begin{tabular}{ll}
\hline Version One & \\
Immediate reward & Delayed reward \\
A small notebook & A large notebook \\
Five balloons & Seven balloons \\
One comic book & Two comic books \\
One small chocolate bar & Two small chocolate bars \\
A small bouncy ball & A large bouncy ball \\
Version Two & \\
Immediate reward & \\
One packet of polos & Delayed reward \\
20 Pence & Two packets of polos \\
Two colouring pencils & 50 Pence \\
One small sheet of stickers & Four colouring pencils \\
A sticker & Two small sheets of stickers \\
\hline
\end{tabular}

Note: The two versions, each with five pairs of choices, used as the measure of delay of gratification. 
were read out aloud, and responses recorded, by the researcher. It was piloted before the study to ensure children understood the method. Participants were instructed to think carefully and choose what they really wanted before the choices were read out to them. The number of delayed choices was counted (maximum 5), with higher scores reflecting a greater ability to delay gratification, and therefore higher self-regulation.

\section{Selective attention}

To investigate a potential cognitive mechanism behind any self-regulation effect due to nature exposure (which would support ART), each participant was asked to complete a version of the Stroop test (Stroop, 1935). This task is widely considered to be a measure of selected attention (MacLeod, 1991) and reflects the ability of an individual's executive functions to inhibit competing attentional demands (i.e. the semantics of a word compared to the colour of the word).

The Stroop measure consisted of fifty colour words presented in 10 rows on a sheet of paper. The words were printed in incongruent ink to the word itself. Two versions of the Stroop task were created for the pre-post stages to reduce learning effects. Following the procedure by Faber Taylor et al. (2002) participants were firstly asked to read through all of the words on the sheet aloud to the researcher. They were then asked to state the colour of the ink each word was printed in. During this part, participants would have to inhibit the impulse to say the word when stating the colour of the ink. The researcher noted how many of the colours the participants said correctly on their first attempt. A higher score reflected a greater ability to maintain selective attention.

\section{Mood measure}

Current mood was measured on a 0-10 scale using a version of Cantril's ladder (Figure 1; Cantril, 1966). Participants were shown the scale and told that the 'number 10 at the very top stands for the happiest you've ever felt'. They were then asked how happy they were feeling 'right now'.

\section{Stimuli}

The natural environment video (Figure 2(a)) consisted of three different scenes shown for one minute each (including sounds), all filmed between February and March 2012 in Cornwall, UK, using a Canon 7D digital camera. The first was a view of a beach from a cliff top, the second was a countryside scene consisting of fields and hedgerows, and the last scene a close up of the shoreline on a beach. The first scene contained people (surfing in the sea), but there was no one in either the second or third views. The only scene that contained buildings was the second scene, but these were in the distance. All three scenes were filmed from a child's eye perspective (approximately three foot from the ground), and were filmed in dry and clear weather.

The urban environment video (Figure 2(b)) was filmed in Truro, a small city in Cornwall, UK, using the same camera at the same time of year in the same weather conditions. Again the video consisted of three different one minute views, this time of different streets within the city. People were present in all three of the scenes, and traffic was present in one of them. Again the three scenes were filmed from a child's eye perspective.

The control 'video' (Figure 2(c)) was the Windows screensaver 'Ribbons', obtained through the control panel of the laptop. It had no sound. This was shown to participants in the control condition for three minutes (the same amount of time as the other two videos).

\section{Procedure}

Participants were tested in spare classrooms within the schools, assessed for suitability by the researcher before the experiments took place. Each participant was tested individually, during afternoon school time. Participants were briefed about the study in accordance with ethical protocols and written consent was gained. 


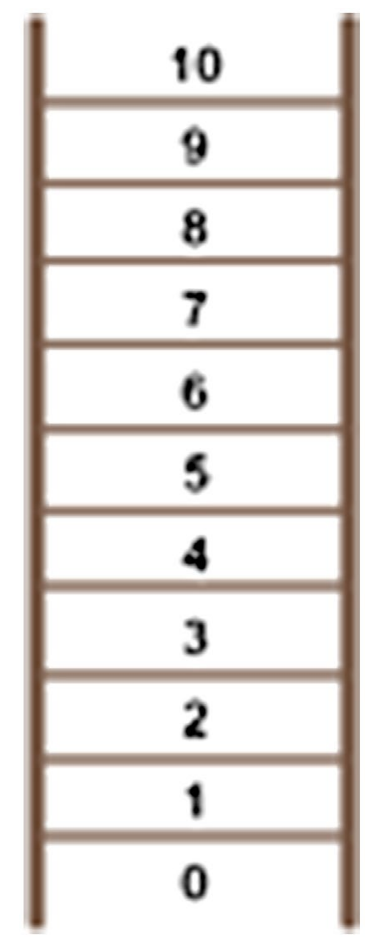

Figure 1. The mood measure.

Note: The picture of a ladder (based on Cantril's ladder) that was printed on to an A4 sheet of paper and used to measure pre-test and post-test mood.

Participants were then given the Stroop (selective attention), delay of gratification (self-regulation) and mood measures, before being randomly assigned to a video condition. In order to reduce possible experimenter bias, a second researcher was in charge of showing the participants the videos to enable the main researcher to be blind to condition (Rosenthal, 1963). In every condition, participants were told they were going to watch a video, and in the natural and urban video conditions participants were additionally instructed to imagine that they were not in school but in the place that the video showed.

After the video finished, the researcher returned and participants again completed the second versions of the selective attention, self-regulation and mood measures. Order of measure versions (pre or post) were counterbalanced across participants. Finally, participants were debriefed, thanked and received a gift (one of the choices in the delay of gratification measure) for taking part.

\section{Statistical analysis}

The researchers remained blind to participant condition during the analysis; the conditions were only revealed once the analysis had been completed. To test the hypothesis that children's self-regulation significantly increased after exposure to natural environments and significantly decreased after exposure to urban environments the post-video delay of gratification scores were analysed using between participant analyses of covariance (ANCOVA), controlling for pre-test delay of gratification scores. Further, in addition to the omnibus test, specific planned contrasts were conducted between each pair of conditions to test whether there were significant differences between (a) Natural and Urban; (b) Natural and Control and (c) Urban and Control. These comparisons were important for testing our hypotheses (regardless of the significance of the overall omnibus test) though in order to reduce the chance of Type 2 errors, significance was set at $p<.01$ for these contrasts. 

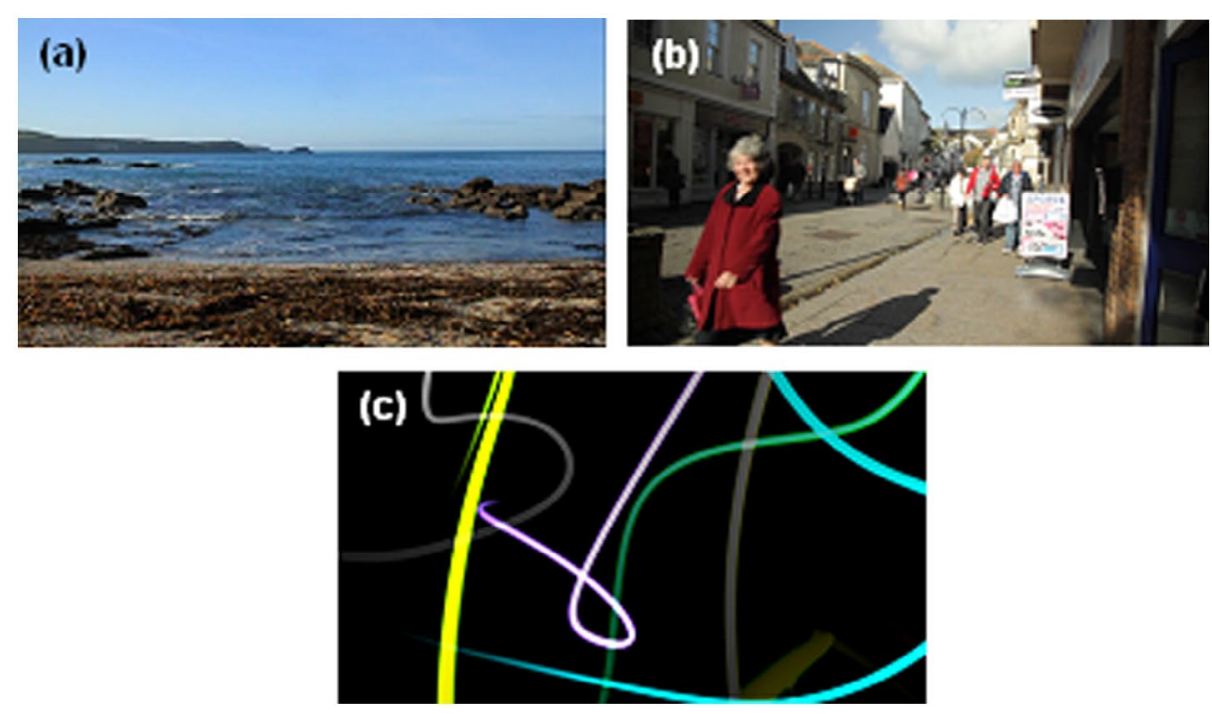

Figure 2. Screenshots of the video scenes. Examples of the stimuli used in the (a) natural, (b) urban and (c) control environment conditions.

To explore the mechanisms behind any effects, separate between participant ANCOVAs and specific contrasts (as above) were also carried out for the attention and mood scores (controlling for pre-test scores). If these were significant regression analysis (Baron \& Kenny, 1986) was performed to determine if mood or attention mediated the relationship between the videos and the self-regulation scores.

The analyses were re-run if outliers (defined as any value whose distance from the nearest quartile is greater than 1.5 times the interquartile range: the standard definition of outliers on IBM SPSS Statistics) were found in the data to ensure these did not substantively affect results.

\section{Results and discussion}

Four of the 79 participants were excluded from the research, either because they opted out during testing or due to equipment failure. A total of 75 participants were included in the final analysis. The pretest and post-test self-regulation and mood scores means and standard deviations by video condition (urban, natural and control) were calculated and can be seen in Table 2.

\section{Self-regulation}

There was a main effect of pre-test self-regulation scores (the covariate), $F(1,71)=30.06, p<.001, \eta^{2}=.30$; participants with higher pre-test delay of gratification scores had higher post-test scores. There was also a statistically significant effect of condition $F(2,71)=5.83, p=.005, \eta^{2}=.14$.

Planned contrasts revealed significant differences between the urban vs. nature condition $(p=.005)$, and the urban vs. control condition ( $p=.004)$. There was no significant difference between the nature vs. control condition $(p=.93)$. The means (see Table 2 ) suggest that participants in the urban condition chose more immediate rewards post-test than pre-test, suggesting their ability to delay gratification decreased after exposure to the urban environment. In the other two conditions the number of immediate and delayed choices did not change significantly, indicating that the ability to delay gratification did not change. In other words, hypothesis 1 was only partially met, as although self-regulation decreased in the urban condition, there was no significant improvement following exposure to nature. No outliers were found, and so the analysis was not repeated. 
Table 2. Self-regulation and mood scores across the studies.

\begin{tabular}{|c|c|c|c|c|c|c|c|c|}
\hline \multirow[b]{3}{*}{ Study } & \multirow[b]{3}{*}{ Condition } & \multirow[b]{3}{*}{$N$} & \multicolumn{2}{|c|}{ Delaying gratification } & \multicolumn{2}{|c|}{ Attention } & \multicolumn{2}{|c|}{ Mood scores } \\
\hline & & & Pre-test & Post-test & Pre-test & Post-test & Pre-test & Post-test \\
\hline & & & $M(\mathrm{SD})$ & $M(\mathrm{SD})$ & $M(\mathrm{SD})$ & $M(\mathrm{SD})$ & $M(\mathrm{SD})$ & $M(\mathrm{SD})$ \\
\hline & Urban & 25 & $3.20(1.87)$ & $2.52(1.61)$ & $44.76(3.64)$ & $46.20(3.38)$ & $7.92(1.58)$ & $8.24(1.73)$ \\
\hline \multirow[t]{3}{*}{1} & Natural & 25 & $3.12(1.51)$ & $3.44(1.36)$ & $45.68(3.21)$ & $47.44(2.52)$ & $7.04(1.46)$ & $7.50(2.36)$ \\
\hline & Control & 25 & $3.40(1.35)$ & $3.60(1.12)$ & $44.20(4.95)$ & $45.80(3.92)$ & $7.50(1.44)$ & $7.30(2.13)$ \\
\hline & Urban & 28 & $3.46(1.04)$ & $2.96(1.07)$ & $37.43(11.34)$ & 39.82 (10.92) & $6.98(1.22)$ & $7.34(1.39)$ \\
\hline \multirow[t]{2}{*}{2} & Natural & 26 & $3.04(1.78)$ & $3.27(1.25)$ & $40.12(11.48)$ & $42.65(9.58)$ & $7.19(1.61)$ & $8.46(1.56)$ \\
\hline & Control & 26 & $2.96(1.08)$ & $2.77(1.18)$ & $39.46(11.95)$ & $41.23(9.50)$ & 7.39 (1.44) & $7.56(1.81)$ \\
\hline
\end{tabular}

Note: Means and standard deviations for the pre-test and post-test delaying gratification, attention, and mood scores by video condition across the two studies.

\section{Selective attention}

There was a significant main effect of pre-test selective attention scores (the covariate), $F(1,71)=81.94$, $p<.001, \eta^{2}=.54$. Participants with high pre-test selective attention scores also had high post-test scores. There was, however, no effect of condition, $F(2,71)=4.15, p=.799, \eta^{2}=.02$.

Planned contrasts also revealed no significant difference between the urban and the natural environment video conditions $(p=.296)$, between the urban and control conditions $(p=.926)$, or between the natural and control video conditions $(p=.259)$. Overall there was no effect of the different videos on the selective attention scores. Re-running the analyses without five outliers did not substantively affect results. The results provide no support for the hypothesis that children's selective attention, as measured by the Stroop, improves after a brief exposure to a virtual natural environment.

\section{Mood after exposure to a natural, urban or control environment video}

There was again a significant effect of pre-test mood scores (the covariate), $F(1,71)=28.85, p<.001$, $\eta^{2}=.29$. Participants with high pre-test mood also had high post-test mood. There was no effect of condition, $F(2,71)=.92, p=.405, \eta^{2}=.03$.

Planned contrasts also revealed no differences between the urban vs. nature conditions $(p=.881)$, the urban vs. control conditions ( $p=.221)$, or the nature vs. control condition $(p=.285)$. Repeating the analyses without seven outliers did not substantively affect results. Overall there was no effect of condition on the participant's mood scores, providing no support for the hypothesis that exposure to virtual natural environments might increase children's mood.

In sum, the results of Study 1 suggest that compared to a 3 min exposure to a simulated urban environment, exposure to a simulated natural environment was associated with significantly better selfregulation, as operationalised as the ability to delay gratification. By including both pre- and post-test measures and a neutral condition, this difference appeared to be due to a reduction in self-regulation in the urban condition. We found no improvement in self-regulation in the nature condition, and so hypothesis 1 was only partially supported. Further, there was no support for hypothesis 2, as neither selective attention nor mood was affected by condition.

\section{Study 2}

Due to the lack of significant results in Study 1 using the Stroop test as a measure of selective attention (perhaps because it was not sufficiently sensitive to the manipulation) this measure was replaced in Study 2 with a measure based on the Symbol Digit Modalities test (SDMT; Smith, 2002). The SDMT has been used to measure directed attention in previous studies of the restorative potential of natural environments (Ottosson \& Grahn, 2005; Tennessen \& Cimprich, 1995). Moreover, we also realised that despite the findings, the urban video used in Study 1 was particularly benign, of a quiet county town 
with little traffic or people. To explore the potential of other, more 'typical' urban environments, Study 2 used video scenes in the urban condition with higher traffic volume and more people within them. Also by making the urban environment more 'demanding' in this way it may be easier to explore the underlying cognitive and emotional mechanisms behind any effects on self-regulation.

\section{Methods}

\section{Participants and design}

Eighty-two participants (44 females), who had not taken part in Study 1, aged between eight and eleven years old, took part from three Primary Schools in Cornwall, UK. Again a between-subjects design was used, with pre-test and post-test measures, and three conditions (urban, natural and control). As in Study 1 , three minute videos were used as the intervention and participants were randomly allocated to condition by their participant number.

\section{Measures}

The self-regulation delay of gratification ${ }^{3}$ and mood measures were the same as those used in Study 1. The attention measure was based on the SDMT, and consisted of a sheet of paper with eight rows, each containing a line of 15 symbols with blank boxes underneath. The symbols could be one of nine (all obtained from the symbol box in Microsoft Word). At the top of the page was a key, where the symbols were matched to the numbers one to nine. There were two versions of the SDMT, which used different symbols (for pre-post testing). Participants were given $90 \mathrm{~s}$ to fill in as many of the boxes as possible on a test sheet. Their SDMT score was how many of the boxes they correctly filled in, with a higher score denoting higher attention ratings.

\section{Stimuli}

The natural and control videos were the same as those used in Study 1. The urban video (with sound) was changed, although it was still filmed in Truro, Cornwall, UK, using the same camera. Three different scenes were chosen, with more people and traffic within them, than the three scenes that had previously been used. This was, as noted above, to make the urban environment video noisier, as research suggests that noise negatively affects children's self-regulation (Shield \& Dockrell, 2003). Therefore, if noise is a factor influencing children's self-regulation, their self-regulation should be more depleted when using this video (compared to Study 1), and may help to shed clearer light on the underlying mechanisms. The video was also three minutes long, and filmed from a child's eye level. The filming took place on a weekday in October 2013, on a cloudy day.

\section{Procedure}

The basic procedure was the same as for Study 1.

\section{Results and discussion}

Statistical analyses followed the same format as Study 1. Two of the 82 participants opted-out of the study, so 80 participants were included in the analysis. The pre- and post-test delay of gratification, attention, and mood score means and standard deviations by condition are presented in Table 2 .

\section{Self-regulation}

There was a significant main effect of pre-test self-regulation scores (the covariate), $F(1,76)=27.81$, $p<.001, \eta^{2}=.27$. Participants with higher pre-test delay of gratification scores had higher post-test delay of gratification scores. There was, however, no significant effect of condition, $F(2,76)=2.02, p=.140$, $\eta^{2}=.05$. Planned contrasts revealed no differences between the urban vs. nature condition $(p=.075)$, 
the nature vs. control condition ( $p=.099)$, or the urban vs. control condition ( $p=.907)$. This implies that exposure to the different videos had no effect on participants' ability to delay gratification. No outliers were found within the data. These results provide no support for the hypothesis that children's selfregulation improves after a brief exposure to a virtual natural environment.

\section{Attention}

There was a significant main effect of pre-test attention scores (the covariate), $\mathrm{F}(1,76)=250.63, p<.001$, $\eta^{2}=.77$. Participants with high pre-test concentration scores also had high post-test concentration scores. There was again no effect of condition, $\mathrm{F}(2,76)=.28, p=.760, \eta^{2}=.01$. Planned contrasts also revealed no differences between the urban vs. nature condition $(p=.555)$, the nature vs. control condition $(p=.496)$, or the urban vs. control condition $(p=.920)$. Repeating the analyses without three outliers did not substantively affect results. Again, as in Study 1, these results provide no support that attention increases after a brief exposure to a virtual natural environment.

\section{Mood}

There was a significant main effect of pre-test mood scores, $F(1,76)=44.01, p<.001, \eta^{2}=.37$. Participants with higher pre-test mood scores had higher post-test mood scores. This time, however, there was a significant effect of condition on mood, $F(2,76)=5.50, p=.006, \eta^{2}=.13$.

Planned contrasts revealed significant differences in the post-test mood scores, controlling for pretest mood, between the nature vs. urban condition $(p=.006)$, and the nature vs. control condition $(p=.005)$. The difference between urban vs. control was not significant $(p=.879)$. The means suggest that the mood scores were significantly higher post-test in the natural environment condition but not in either the control or urban conditions. Removing four outliers did not significantly affect the results.

In sum, Study 2 provided support that children's mood increased after a brief exposure to virtual natural environments, compared to urban and control conditions. However, this finding may be due to using a different video in the urban condition, which showed cloudy weather conditions. Yet this would not explain the difference between the natural and control environment conditions.

\section{General discussion}

Overall, the findings partially support the hypothesis that children's self-regulation capacities were significantly better after a short exposure to a virtual natural environment in comparison to exposure to a virtual urban environment. In Study 1, the post-test delay of gratification scores were better in the natural environment condition compared to the post-test scores of the urban built environment condition. This fits in with previous findings (Faber Taylor et al., 2002), which have found a significant positive relationship between children's self-regulatory ability and how green their living surroundings were for girls (and a slight relationship for boys). The current research also explored the mechanisms behind this effect, by investigating the degree to which exposure to different environments affected children's attentional capacity (linking in with ART) and their emotional well-being (related to SRT). However, we found no effect of the different environment videos on attention in either Study 1 or Study 2. Additionally, although some results indicated that the natural environment video increased mood, positive affect did not mediate the relationship between the natural environment video and self-regulation in these studies.

A surprising difference between this research and previous research is that the difference in participants' ability to delay gratification after they had been exposed to different environments seems to be due to urban environments having a negative impact rather than nature being restorative. This does not tie in with the previous studies with adult participants (Berry et al., 2014; Beute \& de Kort, 2014), which have used similar methods and found that natural environments are restorative on self-regulation, including delay of gratification, in comparison to urban and control conditions. The current research 
seems to imply that very short exposures to urban environments can deplete children's capacity to delay gratification, whereas short exposure to natural environments do not appear to have a restorative effect. It could be that children need longer exposure to natural environments to gain the restorative benefits. This finding furthers the understanding of the dose-response relationship, as it suggests that short doses of nature may not have the same benefits for children, as it appears to for adults.

The finding that children's delay of gratification ability is depleted after exposure to urban environments could be because of factors that influence self-regulation, such as noise, mood and stress (Muraven \& Baumeister, 2000). Urban environments tend to be noisier than natural environments, and research suggests that chronic noise negatively affects children's self-regulation (Shield \& Dockrell, 2003). This was tested in Study 2 by using an urban video that was noisier, but found no significant results. However, there could also be other factors that are influencing children's self-regulation in different environments. Children's self-regulation is negatively affected by stress (Wang, Karns, \& Meredith, 2003), and natural environments have been found to buffer children from the effects of stressful life events (Wells \& Evans, 2003). Overall these could be contributing factors to children's self-regulatory ability to delay gratification becoming depleted after exposure to an urban environment.

It has been suggested that children are better at delaying gratification when they are in a good mood (Schwarz \& Pollack, 1977), and the results of Study 2 provide some support that natural environments increase children's mood. In Study 2 it was found that the natural environment condition significantly increased participant's mood in comparison to the urban and control conditions, although children's delay of gratification ability did not change by condition. Therefore, these findings only provide some support for the hypothesis that natural environments increase individuals' mood.

\section{Implications for practice}

Overall, the findings indicate that children's delay of gratification ability can become depleted after exposure to even a very short (three minute) exposure to an urban environment. Therefore, it is important for children living in highly urbanised areas to have the opportunity to spend time away from these types of environments. This may be particularly important in such areas which have high levels of noise and stress, as these factors may have a detrimental effect on self-regulation. There may also be implications for schools in locations where children have to navigate busy, urban environments in order to get there. The intuitive educational response to offer a 'buffer' activity to prepare children for the school day is supported by these results. But more research is required before definitive conclusions can be drawn, especially when there may be other health and well-being benefits of spending time in urban environments for children. For example, research has shown that children complete most of their outdoor physical activity in non-green urban environments (Wheeler, Cooper, Page, \& Jago, 2010).

Poor self-regulation has been linked to health and well-being issues in children. For example, there appears to be a relationship between child obesity and self-regulation (Nederkoorn, Braet, Van Eijs, Tanghe, \& Jansen, 2006), and poor academic achievement and self-regulation (Matthews et al., 2009). The current studies may be important when considering interventions for children at risk of obesity related health disorders or those struggling at school, as it could be that they benefit from interventions that encourage activities based in other environments than urban ones. However, more research is needed to test the robustness of the effect and how and when it translates to these other outcomes.

\section{Limitations and further research}

One limitation of the two studies is the length of exposure to the intervention. Children watched a three minute environment video before post-tests were carried out. This is only a short exposure, which may have contributed to the lack of findings using the attention measures. It could be that had the children been exposed to the environments for longer, they may have performed differently on the post-test measures. It is uncertain how a three minute exposure is generalisable to real-life exposure, which would normally be of a longer duration, although other research has used this short exposure with adult 
participants and found natural environments had a positive effect on adult's ability to control impulses (Beute \& de Kort, 2014). Another issue with generalising it to real life is that children sat passively and watched the videos, which is not a true reflection of what children would do in the real environments.

A further limitation is that it is unclear whether videos of natural and urban environments evoke the same reactions in children as when they are in the actual environments. A meta-analysis of research completed with adult participants found a positive correlation between responses to virtual and real natural environments (Stamps, 2010) suggesting that, at least with adults, responses are similar. However, it is not known if this is similar for children. We also note that the urban video in Study 2 was 'noisier' than that in Study 1, and although the effects on mood were now in the predicted direction, those on self-regulation were no longer significant. We have no clear explanation for this result except to note that clearer operationalisation of environments is needed in future work.

Also post-testing only happened immediately after the environment exposure. Therefore, it is not known if the different environments had longer effects on children's self-regulation and mood. For example, previous research has found health and well-being benefits for children who live in greener areas (Faber Taylor et al., 2002; Wells, 2000; Wells \& Evans, 2003). However, it would have been difficult to measure this in the current studies, as there was no access to children's home environments, and so it could only have been a self-report measure of their living surroundings.

Further we also recognise that during this immediate post-test period we measured a range of outcomes (Stroop, Affect and Self-regulation) and it is unclear how they may have interacted. In an effort to investigate mediating mechanisms it is hard to see how this can be avoided but future research may need to consider these issues in more detail, again perhaps by having longer delays between different measures. We also acknowledge that the Stroop task may also be measuring aspects of self-regulation in that it requires individuals to inhibit automatic reactions. Although our aim here was to mirror the paradigm adopted by Faber Taylor et al. (2002) as closely as possible, we also acknowledge, in keeping with a recent systematic review of attention measures in the field of ART (Ohly et al., 2016), that the field needs to be much clearer in future in its use of measures to tap into attentional and self-regulatory processes and that there are alternative ways in which Stroop scores can be considered (e.g. reaction times in addition to errors, Beute \& de Kort, 2014) that future researchers may also want to examine. Connected to this issue is the need for future work to conduct clear power analysis prior to the studies as the current work may have been underpowered. Again this will depend on a clear rationale for the precise measures of attention and ego-depletion use in the research.

Finally, it was unknown if children were fatigued before the video interventions took place, and so the lack of findings in the natural and control conditions could have been due to children being at their highest level of self-regulation beforehand and therefore having no capacity to increase. We tried to overcome this limitation by having the participants of the study complete an ego-depletion task before initial measures of self-regulation, however there were no differences in subsequent results as a function of whether children successfully completed the task or did not, and so these results were not considered in the analysis section. Further research is required into ego-depletion tasks that successfully deplete children's capacity for self-regulation so these can be used in experimental studies in the future.

Yet, despite the limitations of the studies, there were also key advantages. These are the first experimental studies to date to investigate children's self-regulation in relation to exposure to different environments. Also, in Study 1 the researcher was blind to conditions throughout the procedure and data analysis, reducing experimenter bias that could have affected the results (Rosenthal, 1963).

\section{Conclusion}

These studies have built on previous research by providing supporting evidence that children's delay of gratification ability and mood are better after short exposures to virtual natural environments compared to urban environments. Unlike previous research, the delay of gratification findings indicates this is more likely to be due to significant detrimental effects of the virtual urban environments, rather than the restorativeness of nature. The results also provide some support that mood increases after exposure 
to virtual natural environments. Implications of these results have been discussed, as well as limitations and suggestions for further research.

\section{Notes}

1. Ethical approval for all studies was granted by the University of Exeter Medical School ethics committee with consent for all studies being given from the headteachers, teachers, parent/legal guardians, and the participants themselves before the study took place. All gave written informed consent, except parents/legal guardians, who were given the opportunity to opt-out their child from the research. Further the procedures and measures were piloted with a sub-sample of pupils to ensure appropriateness and to refine the process before testing began. Schools were recruited through convenience sampling.

2. The theory that self-regulation is a limited resource that can become depleted was put forward by Baumeister and his colleagues (Baumeister, Bratslavsky, Muraven, \& Tice, 1998). This depletion of self-control was termed 'ego depletion', and suggests that individual self-control capacities can become fatigued as it is used, similar to how a muscle works (Muraven \& Baumeister, 2000). In many studies investigating self-regulation an ego depletion task is used to deplete participants capacity before their self-regulatory capacity is measured. This has been completed using 'sad' ego depletion videos, with purposefully upsetting content (Tice et al., 2007, Vohs \& Heatherton, 2000), where participants are asked not to show emotion to deplete their capacity.

An ego depletion task was used at the beginning of Study 1 and Study 2, in order to deplete participants' selfregulation capacity before testing. It was felt that using sad videos was unethical due to the participants being young children in this study. Therefore, in Study 1 a funny video was used (supported by the work of Baumeister et al. (1998), who found similar depletion effects for both the sad and funny videos they used in their study). The participants watched a $55 \mathrm{~s}$ video clip of a cat playing a piano, introduced as a 'warm-up' task, which was found during piloting to be very funny. Importantly, participants were asked to suppress their emotions (no smiling or laughing) whilst watching it, since emotion suppression is supposed to be ego-depleting (Baumeister et al., 1998). However, in practice nearly half of the participants were unable to avoid laughing (perhaps reflecting their age compared to the students usually tested using this paradigm) and there were no significant differences in subsequent results as a function of whether the participants suppressed their emotions or not during the video (which would have suggested different levels of ego-depletion). In Study 2 we used the 'monkey business illusion' which involved counting passes between basketball players whilst a person in a gorilla suit appeared, as way of testing how focused participants were on the required task (i.e. did they report the correct number of passes, or were they distracted by the gorilla). Again accuracy in pass completion scores did not seem to play a role in subsequent outcomes, so the effects of both tasks on results for Studies 1 and 2 are not discussed further in the main body of the text.

3. One choice in the delay of gratification task was changed; 'one packet of polos now and two packets of polos in a week' was changed to 'two mint sweets now or 4 mint sweets in a week'. This was to clarify what the choice was, as some participants in the previous study did not know what polos were.

\section{Acknowledgements}

We would like to thank all of the schools, teachers and schoolchildren who took part in the research. We would also like to thank Chloe Thomas and Abigail Weeks for their help with data collection.

\section{Disclosure statement}

No potential conflict of interest was reported by the authors.

\section{Funding}

This research was part of a PhD project, funded by the European Social Fund Convergence Programme for Cornwall and the Isles of Scilly. The European Centre for Environment and Human Health (part of the University of Exeter Medical School) is part financed by the European Regional Development Fund Programme 2007 to 2013 and European Social Fund Convergence Programme for Cornwall and the Isles of Scilly. 


\section{References}

Ashbullby, K. J., Pahl, S., Webley, P., \& White, M. P. (2013). The beach as a setting for families' health promotion: A qualitative study with parents and children living in coastal regions in Southwest England. Health \& Place, 23, $138-147$.

Baron, R. M. \& Kenny, D. A. (1986). The moderator-mediator variable distinction in social psychological research: Conceptual, strategic, and statistical considerations. Journal of Personality and Social Psychology, 51, 1173-1182.

Baumeister, R. F., \& Heatherton, T. F. (1996). Self-regulation failure: An overview. Psychological inquiry, 7(1), 1-15.

Baumeister, R. F., Heatherton, T. F., \& Tice, D. M. (1994). Losing control: How and why people fail at self-regulation. San Diego, CA: Academic Press.

Baumeister, R. F., Bratslavsky, E., Muraven, M., \&Tice, D. M. (1998). Ego depletion: Is the active self a limited resource? Journal of Personality and Social Psychology, 74, 1252-1265.

Baumeister, R. F., Vohs, K. D., \& Tice, D. M. (2007). The strength model of self-control. Current Directions in Psychological Science, 16, 351-355.

Berry, M. S., Sweeney, M. M., Morath, J., Odum, A. L., \& Jordan, K. E. (2014). The nature of impulsivity: Visual exposure to natural environments decreases impulsive decision-making in a delay discounting task. PLoS One, 9, e97915.

Beute, F., \& de Kort, Y. (2014). Natural resistance: Exposure to nature and self-regulation, mood, and physiology after egodepletion. Journal of Environmental Psychology, 40, 167-178.

Cantril, H. (1966). The pattern of human concerns. New Brunswick, NJ: Rutgers University Press.

Dadvand, P., Nieuwenhuijsen, M. J., Esnaola, M., Forns, J., Basagaña, X., Alvarez-Pedrerol, M., ... Sunyer, J. (2015). Green spaces and cognitive development in primary schoolchildren. Proceedings of the National Academy of Sciences, 112, 7937-7942.

Faber Taylor, A., \& Kuo, F. E. (2009). Children with attention deficits concentrate better after walk in the park. Journal of Attention Disorders, 12, 402-409.

Faber Taylor, A., Kuo, F. E., \& Sullivan, W. C. (2002). Views of nature and self-discipline: Evidence from inner city children. Journal of Environmental Psychology, 22, 49-63.

Graziano, P. A., Kelleher, R., Calkins, S. D., Keane, S. P., \& Brien, M. O. (2013). Predicting weight outcomes in preadolescence: The role of toddlers' self-regulation skills and the temperament dimension of pleasure. International Journal of Obesity, 37, 937-942.

Kahn, P. H. (1997). Developmental psychology and the biophilia hypothesis: Children's affliation with nature. Developmental Review, 17, 1-61.

Kaplan, S. (1995). The restorative benefits of nature: Towards an integrative framework. Journal of Environmental Psychology, $15,169-182$.

Kaplan, S., \& Berman, M. G. (2010). Directed attention as a common resource for executive functioning and self-regulation. Perspectives on Psychological Science, 5, 43-57.

Lee, K. E., Williams, K. J., Sargent, L. D., Williams, N. S., \& Johnson, K. A. (2015). 40-second green roof views sustain attention: The role of micro-breaks in attention restoration. Journal of Environmental Psychology, 42, 182-189.

Leith, K. P., \& Baumeister, R. F. (1996). Why do bad moods increase self-defeating behavior? Emotion, risk tasking, and selfregulation. Journal of Personality and Social Psychology, 71, 1250.

MacLeod, C. M. (1991). Half a century of research on the Stroop effect: An integrative review. Psychological Bulletin, $109,163$.

Matthews, J., Ponitz, C. C., \& Morrison, F. J. (2009). Early gender differences in self-regulation and academic achievement. Journal of Educational Psychology, 101, 689.

McCurdy, L. E., Winterbottom, K. E., Mehta, S. S., \& Roberts, J. R. (2010). Using nature and outdoor activity to improve children's health. Current Problems in Pediatric and Adolescent Health Care, 40, 102-117.

Moffitt, T. E., Arseneault, L., Belsky, D., Dickson, N., Hancox, R. J., Harrington, H., ... Ross, S. (2011). A gradient of childhood self-control predicts health, wealth, and public safety. Proceedings of the National Academy of Sciences, 108, $2693-2698$.

Muraven, M., \& Baumeister, R. F. (2000). Self-regulation and depletion of limited resources: Does self-control resemble a muscle? Psychological Bulletin, 126, 247-259.

Nederkoorn, C., Braet, C., Van Eijs, Y., Tanghe, A., \& Jansen, A. (2006). Why obese children cannot resist food: The role of impulsivity. Eating Behaviors, 7, 315-322.

Nederkoorn, C., Coelho, J. S., Guerrieri, R., Houben, K., \& Jansen, A. (2012). Specificity of the failure to inhibit responses in overweight children. Appetite, 59, 409-413.

Ohly, H., White, M. P., Wheeler, B. W., Bethel, A., Ukoumunne, O. C., Nikolaou, V., \& Garside, R. (2016). Attention restoration theory: A systematic review of the attention restoration potential of exposure to natural environments. Journal of Toxicology and Environmental Health, Part B, 19, 305-343.

Ottosson, J. \& Grahn, P. (2005). A comparison of leisure time spent in a garden with leisure time spent indoors: On measures of restoration in residents in geriatric care. Landscape Research, 30, 23-55.

Rosenthal, R. (1963). On the social psychology of the psychological experiment: 1,2 the experimenter's hypothesis as unintended determinant of experimental results. American Scientist, 51, 268-283.

Schwarz, J. C. \& Pollack, P. R. (1977). Affect and delay of gratification. Journal of Research in Personality, 11, 147-164.

Seeman, G., \& Schwarz, J. C. (1974). Affective state and preference for immediate versus delayed reward. Journal of Research in Personality, 7, 384-394.

Shield, B., \& Dockrell, J. (2003). The effects of noise on children at school: A review. Building Acoustics, 10, 97-116. 
Smith, A. (2002). Symbol digit modailities (SDMT) test: Manual (revised). Los Angeles, CA: Western Psychological Services.

Stamps, I. A. E. (2010). Use of static and dynamic media to simulate environments: A meta-analysis 1. Perceptual and Motor Skills, 111, 355-364.

Stroop, J. R. (1935). Studies of interference in serial verbal reactions. Journal of Experimental Psychology, 18, 643.

Tennessen, C. M., \& Cimprich, B. (1995). Views to nature: Effects on attention. Journal of Environmental Psychology, 15, 77-85.

Tice, D. M., Baumeister, R. F., Shmueli, D., \& Muraven, M. (2007). Restoring the self: Positive affect helps improve self-regulation following ego depletion. Journal of Experimental Social Psychology, 43, 379-384.

Ulrich, R. S. (1983). Aesthetic and affective response to natural environment. In I. Altman \& J. F. Wohlwill (Eds.), Human Behavior and Environment, (Vol. 6, pp. 85-125). New York, NY: Plenum Press.

Ulrich, R. S., Simons, R. F., Losito, B. D., Fiorito, E., Miles, M. A., \& Zelson, M. (1991). Stress recovery during exposure to natural and urban environments. Journal of Environmental Psychology, 11, 201-230.

van den Berg, L., Pieterse, K., Malik, J. A., Luman, M., Willems van Dijk, K., Oosterlaan, J., \& Delemarre-van de Waal, H. A. (2011). Association between impulsivity, reward responsiveness and body mass index in children. International Journal Obesity, 35, 1301-1307.

Vohs, K. D., \& Heatherton, T. F. (2000). Self-regulatory failure: A resource-depletion approach. Psychological science, 11, 249-254.

Vohs, K. D., \& Baumeister, R. F. (2011). Handbook of self-regulation: Research, theory, and applications. New York, NY: Guilford Press.

Wang, A., Karns, J. T., \& Meredith, W. (2003). Motivation, stress, self-control ability, and self-control behavior of preschool children in China. Journal of Research in Childhood Education, 17, 175-187.

Wells, N. M. (2000). At home with nature: Effects of "greenness" on children's cognitive functioning. Environment and Behavior, 32, 775-795.

Wells, N. M., \& Evans, G. W. (2003). Nearby nature: A buffer of life stress among rural children. Environment and Behavior, 35, 311-330.

Wheeler, B. W., Cooper, A. R., Page, A. S., \& Jago, R. (2010). Greenspace and children's physical activity: A GPS/GIS analysis of the PEACH project. Preventive Medicine, 51, 148-152. 